\title{
EVOLUÇÃO DO USO DO COMPUTADOR NO ENSINO DE LÍNGUAS
}

\author{
Francisca Helga Savir Moreira*
}

$\mathrm{H}$

á cerca de 50 anos alguns pesquisadores, investigando as possibilidades trazidas pelos computadores aos propósitos educacionais, inauguraram a Instrução Assistida por Computador (Computer-Assisted Instruction - CAI) enquanto campo de investigação. Atualmente, o termo designa programas de computador desenvolvidos para o ensino, enquanto a Aprendizagem de Línguas Assistida por Computador (Computer-Assisted Language Learning - CALL) pode ser definida como a procura e o estudo de aplicações do computador no ensino e aprendizagem de línguas. ${ }^{1}$ Apesar de serem desenvolvimentos de uma origem comum, a existência da CALL na literatura acadêmica é mais recente, reconhecidamente os últimos 30 anos. Segundo Levy, ${ }^{2}$ enquanto área possibilitada pela invenção e posterior desenvolvimento do computador, a sua natureza em qualquer tempo em particular é um reflexo do desenvolvimento da tecnologia.

Acreditamos que essa natureza seja também um reflexo das teorias de ensino e aprendizagem que informaram a sua utilização ao longo do tempo. Mesmo que a tecnologia se transforme muito mais rapidamente do que as abordagens de ensino de línguas, a sua utilização será guiada pela necessidade

* Universidade Estadual do Ceará/Funcap.

1 LEVY, M. Computer-Assisted Language Learning: concept and conceptualization. New York: Oxford University Press, 1997. p. 1.

2 Ibid., p. 1. 
de atuar como agente facilitador ou enriquecedor da aprendizagem de acordo com essas abordagens. Além disso, a natureza desse campo de estudo é notadamente interdisciplinar, sendo influenciada pela Lingüística Aplicada, a Psicolingüística, a Lingüística Computacional e, mais recentemente, pela Inteligência Artificial, o que o torna ainda mais multifacetado.

A fim de delinearmos mais claramente a relação entre teorias de aprendizagem de línguas, métodos e abordagens de ensino e o uso do computador enquanto recurso de ensino, usaremos a divisão em três fases distintas de Warschauer, ${ }^{3} \mathrm{em}$ seu artigo de introdução à CALL: behaviorista, comunicativa e integrativa. Como o autor observa, a emergência de uma nova fase não implica na rejeição dos programas e métodos da fase anterior e, como ocorre com todas as inovações, a aceitação ocorre de forma lenta e desigual.

\section{CALL behaviorista}

Essa fase, concebida nos anos 50 e implementada nas duas décadas seguintes, recebe esta denominação devido à sua intrínseca relação com a concepção behaviorista do conhecimento, uma das primeiras abordagens teóricas na busca de uma explicação de como as pessoas aprendem. Sua aplicação ao ensino de línguas preconizava a imitação, memorização, repetição e a formação de hábitos "desejáveis" como o caminho para o aprendizado. Acreditava-se que, assim como as crianças imitam e repetem os sons da língua materna, recebendo reforço positivo, e continuam a produzir elocuções até formarem "hábitos" de uso correto da língua, imitação e prática deveriam ser fundamentais para o aprendizado de uma língua.

O computador, nesse contexto, emerge como contribuição de grande valor, uma vez que a máquina não se cansa de repetir a mesma prática até que o aluno acerte a resposta (vale lembrar que o erro, nessa concepção, figura como componente indesejável) apresentando as mesmas explicações incansavelmente. Apesar das dificuldades que caracterizaram essa época, relacionadas aos altos custos e à complexidade dos equipamentos (os sistemas eram desenvolvidos para computadores do tipo mainframe), várias possibilidades interessantes foram

3 WARSCHAUER, M. Computer-Assisted Language Learning: an introduction. In: FOTOS, S. (Ed.). Multimedia Language Teaching. Tóquio: Logos International, 1996. Disponível em: <http://www.lll.hawaii.edu/web/faculty/markw/call.htm> 
percebidas, como o feedback diferenciado e a individualização do ensino, permitindo ao aprendiz passar pelas rotinas no seu próprio ritmo.

A teoria predominante era, como definiu Stern, "pedagogicamente áudiolingual, psicologicamente behaviorista e lingüisticamente estruturalista". ${ }^{4}$ Tais influências podem ser constatadas nos tão amplamente difundidos laboratórios de línguas típicos dessa fase. A essência dos laboratórios, até recentemente, era o fato de proverem os aprendizes com acesso ilimitado ao modelo que devia ser seguido: os falantes nativos da língua gravados nas fitas de áudio. Os computadores, assim como os recursos dos laboratórios, funcionavam como ferramentas provedoras da instrução programada difundida por B. F. Skinner: "o conhecimento elaborado como procedimentos de ensino cujas atividades são apresentadas de modo encadeado, numa seqüência rígida de conteúdos, com permissão de volta repetitiva e mecânica aos itens já estudados quando a resposta do aluno não coincidir com aquela esperada pela CAI."5

A obra de Skinner, The Science of Learning and the Art of Teaching, publicada em 1954, influenciou tanto essa fase que muitos acreditam ter sido ele o fundador do behaviorismo quando na verdade esse papel deve ser atribuído a John B. Watson quase trinta anos antes. Nessa obra de Skinner surge o conceito da "máquina de ensinar": o computador, encarregado de prover o aprendiz com instrução e prática, substituiria ao menos em parte o professor. De acordo com essa concepção, o computador assume o papel de tutor.

Os princípios básicos que nortearam esta fase são sintetizados por Levy: ${ }^{6}$

- $\quad$ aprendizado dividido em passos distintos de forma altamente diretiva;

- $\quad$ desenvolvimento de aplicações para áreas mais "programáveis" da língua (morfologia, sintaxe, vocabulário);

- $\quad$ treinamento de aspectos da língua de forma isolada;

- $\quad$ fornecimento de feedback imediato;

- $\quad$ aprendizado no ritmo particular de cada aprendiz.

4 Apud LEVY, op. cit., p. 14

5 OLIVEIRA, C. C. de; COSTA, J. W.; MOREIRA, M. Ambientes informatizados de aprendizagem. Campinas: Papirus, 2001. p. 76.

6 LEVY, op. cit., p. 52. 
Focalizava-se a forma em vez do conteúdo, a precisão lingüística em vez da fluência comunicativa, verificada na manipulação mecânica de rotinas de exercícios ${ }^{7}$ por professores e alunos.

Uma das críticas que emergiram acerca dessa prática, por volta do final dos anos 70, a considerava não só entediante como também ineficaz. A idéia de a exposição repetitiva ao mesmo material ser considerada benéfica e necessária ao aprendizado foi contestada por estudos que constataram que os aprendizes, diferentemente das máquinas, não eram incansáveis nem podiam trabalhar incessantemente em rotinas de exercícios.

Antes disso, a teoria behaviorista havia sido desacreditada, entre outros, por Noam Chomsky, no final dos anos 50. Segundo Chomsky, todos os humanos nascem com um mecanismo interno de aquisição de linguagem que é acionado através de input, ou insumo lingüístico. As crianças, na verdade, não precisam ser ensinadas: se o ambiente é favorável (existência de pessoas para falar com a criança), é a herança biológica que vai fazer com que adquiram a língua. Embora Chomsky não tenha se referido à aquisição de segunda língua ou de língua estrangeira, suas idéias (conhecidas como "inatistas") influenciaram vários teóricos e conduziram a teorias de grande impacto, como por exemplo, as difundidas por Krashen.

Uma crítica bastante interessante sobre a crença de que aprendizagem equivale ao fortalecimento dos laços entre estímulo e resposta pode ser encontrada no artigo de Berryman ${ }^{8}$ sobre ambientes de aprendizados eficazes. De acordo com a autora, a instrução baseada nessa suposição emerge de uma teoria de aprendizagem que resulta em um currículo de itens desconexos e fragmentados, inexistindo um entendimento do contexto no qual esses itens se encaixam. Essa abordagem não considera os seres humanos como essencialmente fazedores de sentido e solucionadores de problemas.

Como aponta Levy, ${ }^{9}$ essa visão altamente estruturada do ensino e aprendizagem de línguas facilitou o desenvolvimento de materiais no computador, uma vez que os princípios por trás da teoria podiam corresponder facilmente às capacidades da máquina. Na fase seguinte, entretanto, como veremos a seguir, a relação entre pedagogia e tecnologia se torna mais tênue e complexa.

7 A palavra drill foi traduzida pela autora neste trabalho como rotinas de exercício.

8 BERRYMAN, S. E. Designing effective learning environments: cognitive apprenticeship models. Resumo do trabalho BERRYMAN, S. E. Cognitive Science: Challenging schools to design effective learning environments. New York: Columbia University, 1991. Mimeog.

9 LEVY, op. cit., p. 7. 


\section{CALL comunicativa}

A rejeição da teoria lingüística que sustentava o método áudio-lingual nos Estados Unidos na metade dos anos 60 e o questionamento das bases teóricas da abordagem situacional conduziram à busca por um novo paradigma. A abordagem situacional (também conhecida como abordagem oral), desenvolvida entre os anos 30 e 60 por lingüistas aplicados ingleses, considerava, como no método áudio-lingual, o discurso oral como a base da língua, cujas formas selecionadas deveriam ser praticadas com bastante frequência. Havia ênfase na linguagem usada em contextos típicos de comunicação cotidiana e atividades baseadas nas situações em que os alunos necessitariam usar o idioma. Entretanto, a premissa de previsibilidade da língua com base em eventos situacionais foi refutada, ao mesmo tempo em que percebeuse uma inadequação entre as abordagens de ensino de línguas existentes e uma dimensão fundamental da língua: o seu potencial funcional e comunicativo.

Ao mesmo tempo, uma transformação na realidade educacional européia, pressionada pela maior interdependência entre os países e a necessidade de ensinar a adultos as principais línguas do mercado comum europeu, conduz à procura de novas abordagens de ensino.

Nessa época, o behaviorismo já havia sido contestado de várias formas, especialmente por representantes da corrente dita interacionista, como Vygotsky, Wallon e Piaget. O reflexo dessa corrente no ensino de línguas revelava que, ao contrário do que pensavam os defensores do behaviorismo, os aprendizes não necessitavam exclusivamente de input, mas também da interação com outras pessoas e da negociação de significado para efetivamente se comunicarem.

Nesse cenário, um fato que exerce papel de extrema importância é a emergência do conceito de competência comunicativa, primeiramente usado por Dell Hymes em 1972. Em contraste com o conceito de competência lingüística defendido por Chomsky, segundo o qual "o foco da teoria Lingüística era caracterizar as habilidades abstratas que os falantes possuem que os capacitam a produzir sentenças gramaticalmente corretas," ${ }^{10}$ Hymes considerava que a teoria lingüística deveria ser mais abrangente incorporando comunicação e cultura. A sua teoria de língua, enquanto comunicação, conduz à amplamente disseminada abordagem comunicativa, que denomina esta segunda fase de desenvolvimento.

10 RICHARDS, J. C.; RODGERS, T. S. Approaches and Methods in Language Teaching. Cambridge: Cambridge University Press, 1986. p. 70. 
As transformações são profundas: ao contrário do método áudio-lingual, o significado adquire precedência sobre a estrutura e a forma, a contextualização passa a ser premissa básica e a memorização de diálogos baseados em estruturas da língua praticamente desaparece, uma vez que agora se almeja a comunicação efetiva na língua-alvo. O erro deixa de ser um componente a ser evitado a qualquer custo, uma vez que é aceito como parte integrante do aprendizado. Fundamentalmente, muda o conceito predominante de aprendizagem de línguas: aprender passa a não significar mais o domínio de palavras, sons ou estruturas; essencialmente, o aprendizado implica em adquirir competência comunicativa, ou seja, "a habilidade de usar o sistema lingüístico de forma eficiente e apropriada." 11

Paralelamente, temos o advento dos computadores pessoais, que em nada se assemelham às enormes máquinas dos primórdios da CAI que, como já foi dito, eram também extremamente caras e complicadas de operar. A redução no custo e na complexidade operacional contribuem para que os computadores sejam usados nas mais variadas áreas do conhecimento humano - tendência que pode ser observada com eloqüente intensidade nos dias de hoje. $\mathrm{O}$ computador continua, como diz Warschauer, o detentor da resposta correta, ${ }^{12}$ só que desta vez com uma mudança substancial no modo como chegar à essa resposta, envolvendo muito mais controle por parte do aprendiz, que precisa fazer escolhas próprias. Além de tutor, o computador assume também a função de ferramenta e estímulo ao pensamento crítico e à interação que leva o aprendiz a entender e produzir a língua.

A esse respeito, é interessante mencionar aqui a conceitualização de Taylor: ${ }^{13}$ enquanto tutor, o computador apresenta o material, o aluno responde, o computador avalia a resposta e, a partir dessa avaliação, determina o que apresentar em seguida. Presume-se que o professor não esteja presente ou participe, e a metodologia de ensino é predominantemente atrelada ao programa do computador. Enquanto ferramenta, o computador é encarado como um dispositivo de auxílio para completar tarefas de forma mais produtiva, é desprovido de função de controle direto e não comporta uma metodologia em si: cabe a professores e aprendizes usá-lo eficientemente para atingir os objetivos de aprendizagem de seu contexto específico. Não se espera que o computador ensine a língua, mas que atue como instrumento enriquecedor ou facilitador da aprendizagem.

11 RICHARDS; ROGERS, op. cit., p. 67.

12 knower-of-the-right anwer. Tradução da autora.

13 Apud LEVY, op. cit., p. 83. 


\section{CALL Integrativa}

A fase anterior predomina até o final dos anos 80 , quando se faz necessária a construção de um novo paradigma que comporte as mudanças trazidas pelo advento da internet e dos computadores multimídia, gerando a terceira fase, a CALL Integrativa, ${ }^{14}$ que é a que vivenciamos agora, caracterizada por abordagens baseadas no uso de computadores multimídia e a internet. Através desta última, é possível se comunicar 24 horas por dia, simultaneamente ou não, de forma rápida, conveniente e barata com nativos da língua que se deseja aprender. Pode-se, inclusive, conversar com várias pessoas ao mesmo tempo, fazer intercâmbio de imagens e sons, localizar materiais autênticos de acordo com os interesses de cada um. Paralelamente, através de recursos trazidos pela tecnologia multimídia, temos sons, vídeo, animações, textos e gráficos trabalhando conjuntamente para combinar leitura, escrita e habilidades orais em uma mesma atividade, além de proporcionar mais controle por parte do aluno sobre o seu próprio aprendizado.

Segundo Levy, ${ }^{15} \mathrm{o} e$-mail e a internet quebram as barreiras definidas por recursos humanos e materiais em um só local, levando a possibilidades de aprendizado incomensuráveis. Com a quebra dos limites tradicionais da sala de aula, professores e alunos são agora capazes de ir muito além do seu ambiente de aprendizado localmente definido. Isso possibilita, por exemplo, a participação ativa de falantes nativos da língua no processo de aprendizagem.

Os anos 90 também trazem evidências advindas de vários estudos em CALL sobre a contribuição de aplicações desta área para ativar conhecimento implícito e explícito, aumentar a motivação intrínseca e desenvolver processos de aprendizagem. ${ }^{16}$ Tomemos como exemplo o conceito de "filtro afetivo", de Krashen: aquele que adquire a língua deve estar aberto ao input, isto é, interessarse em compreendê-lo, porque de outra forma um bloqueio mental irá impedir que o input seja absorvido. "O bloqueio ocorre e o filtro é ativado quando o que adquire encontra-se desmotivado, desprovido de autoconfiança, e quando está

14 Integrative CALL.

15 LEVY, op. cit., p. 172.

16 Multhaup explica com bastante clareza estes conceitos: falamos em motivação intrínseca se o aprendiz quer aprender algo porque ele realmente gosta disso; falamos em motivação extrínseca se o aprendiz faz algo porque isso pode servir a propósitos práticos, mesmo que ele possa particularmente não gostar do que está aprendendo. 
na defensiva ou ansioso porque ele considera a aula de línguas um lugar onde suas fraquezas são reveladas." 17

Nesse sentido, uma das maiores contribuições do computador é possibilitar ao aprendiz uma privacidade dificilmente potencializada na sala de aula convencional. Como Brett ${ }^{18}$ explica, o domínio não-público dessa forma de aprendizado pode liberar os aprendizes para explorar áreas que eles não gostariam de admitir não haver compreendido, tomando o tempo do professor e dos outros alunos na sala de aula. Parece ser universal que alunos deixem de fazer perguntas e esclarecer dúvidas durante as aulas por temer comentários pejorativos ou um julgamento negativo por parte dos colegas ou até mesmo do professor.

A multimídia permite aos aprendizes interagir com os materiais de aprendizado em seu próprio ritmo. Aqueles que enfrentam mais dificuldades não se sentem menos aptos ou sob pressão para acompanhar os outros alunos, enquanto aqueles que se encontram no outro extremo podem explorar atividades mais desafiadoras e instigantes. Em ambas as possibilidades, os aprendizes não são passivos, o processo é permeado pela necessidade de realmente se pensar sobre as informações apresentadas e reagir a elas. Vários estudos têm demonstrado que estar envolvido e ativo ajuda os aprendizes na melhoria de sua performance.

É importante enfatizar que tais esquemas favorecem, potencialmente, o aprendizado, mas não conduzem necessaria e invariavelmente a ele. Cabe aqui estender a observação de Férres ${ }^{19}$ sobre o uso do vídeo também a esses sistemas. As melhores possibilidades e as piores limitações do vídeo são provenientes de dois fatores alheios à tecnologia: a qualidade dos programas com os quais se trabalha e a preparação do professor para usar os mesmos de forma criativa e participativa. As vantagens apresentadas em experiências de aprendizagem usando tecnologias ditas "interativas", como redução do tempo de aprendizagem, aumento da retenção, da motivação e da segurança, aprendizagem estimulante (e sobre a qual se tem domínio), acessibilidade, entre outros vai depender fundamentalmente dos fatores mencionados por Ferrés.

17 MULTHAUP, U. History of Approaches to FLT. Disponível em: <http://www.uniwuppertal.de/FB4/anglistik/multhaup/history.htm\#2.1.4> Acesso em: jan. 2001.

18 BRETT, P. Multimedia Applications for Language Learning - What are they and how effective are they. Disponível em: <http://pers-www.wlv.ac.uk/ le1969.htm> Acesso em: dez. 2000.

19 FERRÉS, J. Pedagogia dos meios audiovisuais e pedagogia com os meios audiovisuais. In: SANCHO, J. M. Para uma tecnologia educacional. Tradução de: Beatriz Affonso Neves. Porto Alegre: ArtMed, 1998. p. 141. 


\title{
RESUMO
}

Uma série de teorias de ensino e aprendizagem vêm sucessivamente delineando e informando o ensino de segunda língua e língua estrangeira, refletindo diferentes concepções sobre o que significa aprender e propondo respostas às necessidades de diferentes contextos de aprendizagem. Ao longo dos últimos anos, o computador vem sendo incorporado a esse cenário, firmando-se enquanto instrumento pedagógico potencialmente facilitador do aprendizado. O presente trabalho visa explorar o entrelaçamento entre as teorias acima citadas e o assim chamado ensino de línguas assistido por computador (área conhecida internacionalmente como CALL - Computer-Assisted Language Learning). A fim de demarcarmos mais claramente a relação entre teorias de ensino de línguas, métodos e abordagens de ensino e o uso do computador enquanto recurso didático, usaremos a divisão do desenvolvimento da CALL em três fases, segundo Warschauer (1996): behaviorista, comunicativa e integrativa.

Palavras-chave: Ensino de segunda lingua/lingua estrangeira, ensino de línguas assistido por computador, teorias de ensino e aprendizagem de linguas.

\begin{abstract}
A series of theories has successively been delineating and informing the teaching of second and foreign language, reflecting different conceptions on what it means to learn and proposing answers to the needs of different learning contexts. Over the last few years, the computer has been incorporated into this scenario, being established as a pedagogic instrument that can potentially facilitate learning. This paper intends to explore the weaving between the theories aforementioned and the so-called Computer-Assisted Language Learning (CALL). In order to outline more clearly the relationship among language teaching theories, methods and approaches and the use of the computer as an instructional resource, we will use the division of CALL's development as proposed by Warschauer (1996): behaviorist, communicative and integrative.

Key-words: Second/foreign language teaching, Computer-Assisted Language Learning, language teaching theories.
\end{abstract}




\section{REFERÊNCIAS}

BRETT, P. Multimedia Applications for Language Learning - What are they and how effective are they. Disponível em: <http://pers-www.wlv.ac.uk/ le1969.htm> Acesso em: dez. 2000.

FERRÉS, J. Pedagogia dos meios audiovisuais e pedagogia com os meios audiovisuais. In: SANCHO, J. M. Para uma Tecnologia Educacional. Trad. de: Beatriz Affonso Neves. Porto Alegre: ArtMed, 1998.

LEVY, M. Computer-Assisted Language Learning: concept and conceptualization. Nova York: Oxford University Press, 1997.

MULTHAUP, U. History of Approaches to FLT. Disponível em: < http://www.uniwuppertal.de/FB4/anglistik/multhaup/history.htm\#2.1.4> Acesso em: jan. 2001.

OLIVEIRA, C. C. de; COSTA, J. W.; MOREIRA, M. Ambientes informatizados de aprendizagem. Campinas: Papirus, 2001.

RICHARDS, J. C.; RODGERS, T. S. Approaches and Methods in Language Teaching. Cambridge: Cambridge University Press, 1986.

WARSCHAUER, M. Computer-Assisted Language Learning: an introduction. In: FOTOS, S. (Ed.). Multimedia Language Teaching. Tóquio: Logos International, 1996. p. 3-20. 